\title{
Que nação é esta? Tramas identitárias nas artes visuais portuguesas ${ }^{1}$
}

Resumo

Este artigo procura cartografar a rede de sentidos disseminada a partir da ideia de nação nas artes visuais portuguesas na actualidade, explorando o que anuncia o reforço do debate em torno da identidade nacional. Partindo de uma etnografia do campo artístico, procurar-se-á interpelar as identidades em cena na arte contemporânea portuguesa, questionando sua rede de intencionalidades.

Palavras-chave: Práticas artísticas, nação, Portugal 


\title{
Which nation is this? Entangled identities in Portuguese visual arts
}

SÓNIA VESPEIRA DE ALMEIDA

\begin{abstract}
This article aims to analyse the idea of nation in Portuguese visual arts, exploring what announces the strengthening of

Keywords: Artistic practices, nation, Portugal the debate on national identity. Based on ethnography of the artistic field, I will discuss the network of intentionalities that underlies this tendency of Portuguese arts.
\end{abstract}




\section{Introdução}

A visualidade contemporânea convoca pontos de intersecção entre histórias e geografias nacionais, internacionais e transnacionais, urdindo o local e o global. Nestas dinâmicas o visual assume, nas suas múltiplas dimensões, um papel central ao articular a capacidade de significar e a produção de subjectividades dos sujeitos que resgatam e produzem sentidos (EVANS \& HALL, 2004, 1999). Ao enfatizar esta centralidade, Mitchell convoca o universo literário de José Saramago, em particular a obra Ensaio sobre a Cegueira: "to live in any culture whatsoever is to live in a visual culture, except perhaps for those rare instances of societies of the blind, which for that very reason deserve special attention in any theory of visual culture" (MITCHELL, 2002, p. 174). Numa reflexão anterior (1994), o autor afirma que a imagem é: "a complex interplay between visuality, apparatus, institutions, discourse, bodies and figurality"(1994, p. 16). Cada um destes elementos anuncia um intrincado conjunto de práticas que confere à imagem a capacidade de produção de sentido.

No seu último livro Garcia Canclini (2010), ao interpelar a sociedade "sin relato", afirma que a arte ocupa uma posição de iminência, anunciando o que pode acontecer, prometendo ou modificando sentidos. Nas últimas décadas, a arte contemporânea tem sido modelada por amplas reconfigurações nas quais "todas as competências artísticas específicas tendem a sair do seu domínio próprio e trocar os respectivos lugares e poderes (RANCIÈRE, 2010, p. 33), assistindo-se, tal como sinalizou Garcia Canclini (2010), à expansão da arte para além do seu próprio campo. Contudo, os mundos da arte (BECKER, 1982) permanecem como espaços de con- 
testação, de inclusão e de exclusão, manifestando as posições políticas dos sujeitos. Como afirmam Morphy e Perkins (2006): "Art has increasingly become part of cultural commentary and of political discourse, involving a reflexive critique of the artist's own society" (2006, p. 11).

Neste contexto contemporâneo, a arte assume um papel determinante na medida em que os artistas reificam ou criam significados através das suas práticas e objectos (MACCLANCY,1997, p. 4). Aarteobjectifica identidades, poderes e mundividências importando debater a sua contribuição - e num sentido mais lato, a contribuição do campo artístico - na construção de imaginários partilhados (GARCIA CLANCLINIi, 2005, 1998, p. 181). Contudo, num momento caracterizado pelo hibridismo das comunidades imaginadas (BHABHA, 1994), pela contestação da homogeneidade cultural e no quadro da arte "pósautónoma" (GARCIA CANCLINI, 2010), como situar o debate em torno da nação nas práticas artísticas em Portugal?

Comecemos por afirmar que nas artes visuais portuguesas se desenham duas principais abordagens à nação. Por um lado, a nação é convocada recorrendo-se à cultura popular como idioma principal, aproximando-se de um discurso "etno-simbólico" (SMITH, 2002), num movimento de esteticização do património nacional. Por outro, as práticas artísticas convocam ideias mais pluralistas de nação através de reflexões sobre a conexão de Portugal com o seu antigo império colonial e sobre a memória da Guerra Colonial ${ }^{2}$, dando-se voz aos "subexpostos" (DIDI-HUBERMAN, 2011) da nação. Estamos, assim, na presença de tópicos relacionados com a condição pós-colonial, aqui entendida na esteira de Miguel Vale de Almeida (2002), Stuart Hall (2006, 1996) ou Hommi Bhabha (1994), como um complexo de relações transnacionais entre ex-colónias e ex-metrópoles.

Deste modo, a problemática central deste texto repousa no questionamento das complexidades que decorrem destas duas abordagens, procurando interpelar como se posicionam os artistas, o que insinuam, quais os desconfortos e discussões desenvolvem. O artigo traz, deste modo, à colação as práticas de um conjunto de artistas portugueses ${ }^{3}$, de diferentes gerações, cujo trabalho diverge do ponto de vista formal e técnico mas que se relaciona entre si através dos processos de "imaginação da nação" (ANDERSON, 1991, 1983) que envolve.

Partindo de uma etnografia do trabalho artístico ${ }^{4}$ (BUSCATTO, 2008) interpelarei as identidades em cena na arte contemporânea portuguesa, procurando perceber quais as 
escalas, geografias, espaços, histórias e objectos convocados neste display identitário. No quadro da proposta de Alfred Gell (1998), nomedamente o entendimento da arte enquanto sistema de acção, procurarei cartografar a rede de significações disseminada a partir da ideia de nação, explorando o quadro das interacções que o objecto artístico mobiliza.

\section{A discussão da nação na arte contemporânea portuguesa I: cultura popular como idioma}

No dia 1 de Março de 2010, inaugurou em Lisboa a exposição antológica de Joana Vasconcelos ${ }^{5}$ (Paris, 1973) intitulada Sem rede $^{6}$. Os corredores de acesso às salas que acolhem as exposições temporárias do Museu Colecção Berardo, não deixavam adivinhar a exiguidade daqueles espaços para receber o público que caminhava lentamente pelo itinerário da exposição, disputando, por vezes, um ângulo de observação entre os muitos fotógrafos presentes. Ouviam-se comentários às peças, em tom elogioso e apologético, à semelhança dos que foram sendo colocados na página da artista no Facebook durante o período de vigência da exposição: "Adoro a criatividade e a mensagem na utilização dos materiais... ainda há artistas com o Coração na nação :)"; “Única no mundo a transbordar Portugal”.

Nesta mostra, a obra Coração Independente assumia uma posição de destaque, tendo-lhe sido atribuída um espaço autónomo e intimista. A instalação é composta por três corações, em escala ampliada, realizados com talheres de plástico translúcidos invocando uma técnica de joalharia - filigrana oriunda do Minho (região norte de Portugal). A montagem da instalação possibilitava ao visitante circular pela peça ao som dos fados de Amália Rodrigues.

Este apontamento permite uma primeira aproximação à centralidade da ideia de nação no campo artístico em Portugal no qual são desenvolvidos dialógos com o popular, os símbolos culturais, as "tradições" e a história nacional. As práticas artísticas envolvem, deste modo, a interlocução com a experiência etno-cultural, mobilizando-se a cultura popular como plataforma de negociação identitária e de reflexão sobre a sociedade portuguesa.

Para melhor contextualizar o reforço desta tendência e a sua rede de intencionalidades, importa situá-la diacronicamente, uma vez que durante o século XX material "etno-cultural” (LEOUSSI, 2004) constituiu um reportório convocado pelos artistas portugueses para debater e representar a ideia 
de nação. Em traços largos, em Portugal do Modernismo até à actualidade os diferentes movimentos estéticos, alinhados ou não com o poder, apropriaram-se, de forma diferenciada, de temas e objectos populares ${ }^{8}$.

Neste contexto, o dossiê teórico sobre as identidades nacionais constitui uma entrada analítica relevante para o feixe de problemas que este artigo discute. A nação não é apenas uma entidade política, mas algo que produz sentidos, isto é, configura um sistema de representação cultural (HALL, 2006, 1992, p. 49).

Na linha de Orvar Löfgren (1989) e Anne-Marie Thiesse (2000), entendo as identidades nacionais no seu carácter processual, permitindo montagens diversificadas a partir de um conjunto de categorias, dinâmicas estas cristalizadas nas expressões "do it yourself kit" (LÖFGREN, 1989) e "sistema IKEA" (THIESSE, 200o). Thiesse sugere ainda que é possível construir uma lista dos elementos simbólicos e materiais que uma nação deve oferecer:

uma história que estabelece uma continuidade com os ilustres antepassados, uma série de heróis modelos das virtudes nacionais, uma língua, monumentos culturais, um folclore, locais eleitos e uma paisagem típica, uma determinada mentalidade, representações oficiais - hino e bandeira - e identificações pitorescas [...] (THIESSE, 200o, p. 18).

Consolidando esta linha de argumentação, importa convocar o conceito de "arte nacional" que decorre das formulações de Anthony Smith sobre o etno-simbolismo (SMITH, 1991, 2002). A arte nacional, segundo Athena S. Leoussi (2004), refere-se às práticas artísticas que se inspiram ou se apropriam do património étnico e cultural, tradições, memórias, mitos e paisagem (2004, p. 145). A autora estabeleceu as cambiantes da arte nacional, das quais importa destacar: a representação da história nacional e a sedução dos artistas pela história da sua "comunidade etno-cultural"; o interesse em torno de estereótipos étnicos, símbolos nacionais e a mobilização dos valores etno-culturais periféricos de matriz rural (2004, p. 145).

Neste quadro, as práticas artistas aqui em análise apresentam algumas afinidades com a proposta destes autores sendo possível identificar um reportório dos usos do popular. Retomando o trabalho de Joana Vasconcelos, a ideia de nação é discutida a partir de uma "check-list" identitária, isto é, dos estereótipos e símbolos nacionais e regionais, afirmando 
a artista que a "identidade portuguesa é muito rica porque é muito antiga" . Segundo J. Pinharanda, Joana Vasconcelos está precisamente em sintonia com "as actuais estratégias de comunicação: os elementos são facilmente identificados e descritos, rapidamente localizáveis; partem de um ou vários tipicismos nacionais/regionais para uma rede global de valores de reconhecimento e espectacularização facilitadores da internacionalização [...].” (PINHARANDA, 2010, p. 398).

A relação entre arte e artesanato assume destaque na sua prática artística sobretudo através da relação de colaboração e co-produção com diferentes artesãos. Aquando da minha visita ao seu atelier em Lisboa, a artista preparava-se para nos dias subsequentes, inaugurar a peça Valquíria Enxoval, nas termas da Fadagoza em Nisa (vila situada no Alentejo). Esta peça foi o resultado de uma encomenda do município desta vila que lhe propôs trabalhar a partir da "arte popular" de Nisa. Procurou construir um enxoval - conjunto de peças têxteis que a noiva prepara para o casamento - com o objectivo de reinterpretar o artesanato de Nisa, revelando uma preocupação com o seu "abandono anunciado". Aqui alinhavados, aplicações em feltro, rendas de bilros, pontos de cadeia, xailes, bordados e a olaria pedrada foram apropriados numa instalação que interroga os universos culturais daquela região, interessando-se a artista pelas questões de género e cultura material.

Joana Vasconcelos sublinha que consegue "trasladar da low culture à high culture, ligando uma coisa banal, quotidiana e sem valor ao conceito de escultura contemporânea" (RUBIO, 2007, p. 48), afirmando:

Eu faço questão que a identidade do objecto não seja perdida [...]. Uso de maneira diferente. Descontextualizo é verdade, perspectivo de outra maneira, mas não adultero a identidade. Os portugueses são grandes artesãos. ${ }^{10}$

Deste modo, a artista convoca elementos e objetos, mas também técnicas de manufactura mais lenta, como a utilização do bordado, do croché ou a invocação da filigrana recorrendo a materiais de plástico.

Analogamente, Carlos Noronha Feio" (Lisboa, 1981) no seu projecto $A A$ and away trabalhou com a Casa dos Tapetes de Arraiolos e com a "identidade cultural"12 desta vila do Alentejo. Este projecto ancora-se à sua "própria nacionali- 
dade portuguesa" cruzada com a imagética dos tapetes de guerra afegãos, interessando-lhe as "negociações inter-culturais” (FEIO, 2009, p. 11). Nas palavras do artista:

O meu interesse pelos tapetes de Arraiolos começou pelo meu fascínio pelos tapetes afegãos e por eu querer trabalhar os tapetes afegãos mas tendo consciência de não perceber a cultura toda que está por detrás deles. Tive que arranjar uma maneira sincera de desenvolver esse trabalho. E a única forma sincera é ir ao que é mais perto da minha própria cultura, que eu consiga relacionar de certa forma com esses tapetes afegãos. Entrei pela parte da técnica, que nem sequer é a mesma, mas é o mesmo conceito, é um tapete. E o que me é mais próximo é mesmo Arraiolos, está enraizado na minha própria identidade. ${ }^{13}$

Noronha Feio entende este acto de apropriação como uma colaboração, afirmando que a Casa dos Tapetes de Arraiolos, era "uma das melhores" na produção do tapete "tradicional português" e que "precisava que as peças fossem sinceras, e ao fabricá-las em Arraiolos, elas têm certificados originais, cada um dos meus tapetes vem com um certificado de autenticidade" (FEIO, 2009, p. 12).

Estes processos de "apropriação"14, aqui entendidos na esteira de Arnd Schneider (2003, 2006) e Christopher Wright (SCHNEIDER \& WRIGHT, 2006), são vitais para a problematização das práticas artísticas contemporâneas, permitindo interpelar o carácter processual das dinâmicas identitárias. As apropriações operarem a partir de materiais, técnicas e símbolos próximos do contexto de origem dos artistas, sendo operacionalizados como plataformas para debater a identidade nacional.

Descontextulizado, recontextualizado, ressemantizado, este material etno-cultural é, também, convocado pelos artistas para que a sua obra seja partilhada e apreendida. A narrativa da nação, ancorada no seu kit de elementos "folk", surge como uma plataforma comum que permite a relacionar artistas e públicos. João Pedro Vale ${ }^{15}$ (Lisboa, 1976) tem trabalhado nos últimos anos sobre as identidades de género e desenvolvido um movimento crítico relativamente à identidade nacional. Na entrevista realizada afirma:

O que me interessa mais do que tudo na cultura popular é a aproximação com as pessoas. E quando digo aproximação é: 
tu à partida enquanto espectador já seres detentor de uma série de códigos para interpretar a peça e acima de tudo isso é o que me interessa. ${ }^{16}$

No mesmo sentido, a escultora Ângela Ferreira (Maputo, $1953)^{17}$, ao elaborar um olhar retrospectivo do seu percurso, afirma:

Quando venho para Portugal, a exposição ${ }^{18}$ que eu faço como resultado de ser bolseira é investigar arados. O ponto de interesse dos arados não era o turístico do objecto ou o exótico do objecto. O ponto de interesse era sim eu a procurar objectos que tivessem significado escultórico e popular, no sentido de real.[...]. Essa relação é absolutamente vital e parte de um preceito político muito consciente que diz "eu quero fazer algo contemporâneo que tenha qualidades conceptuais e formais inseridas nesse discurso da contemporaneidade, mas que seja inteligíveis por diferentes níveis culturais e intelectuais da sociedade. E para isso eu tenho que trabalhar a partir de referências, imagéticas neste caso, que sejam automaticamente parte do vocabulário visual do popular. ${ }^{19}$

Em 1989, recebe a bolsa de estudos à qual se candidatara e inicia a sua indagação em torno do "sentido da identidade portuguesa" ${ }^{20}$ afirmando ainda que "nas minhas esculturas e desenhos gostaria de poder celebrar e exultar a cultura portuguesa [...]" e "fazer o transporte de "imagens" portuguesas a outras partes do mundo"21.

O trabalho desenvolvido por estes artistas visuais reforça empiricamente o conceito de "apropriação" ao articular os processos que ligam o artista, os artefactos convocados (e os seus produtores) e as obras que resultam deste processo de apropriação (Schneider, 2006:27). As práticas artísticas encontram-se, assim, viradas para a interlocução com um reportório etno-simbólico, a via que assegura a diferença e a especificidade de "uma comunidade imaginada" (Anderson, 1991). Os artistas reificam, constroem e debatem identidades através de objectos específicos, assumindo um papel de mediação entre as práticas culturais nacionais e os circuitos globais (SCHNEIDER, 2006, p. 16).

Neste sentido, importa sublinhar que as artes visuais ao mobilizarem uma ideia de nação, participam na elaboração de um discurso nacional a partir da cultura popular, o que poderá denunciar um paradoxo num momento em que as culturas nacionais são desafiadas pelos processos de transnacionalismo 
económico e simbólico (GARCIA-CANCLINI, 2005, 1998)Porém, as práticas artísticas aqui em debate revelam precisamente uma das contradições (APPADURAI, 1996, HALL 2006, 1992) amplamente identificadas pelos estudos sobre globalização: a tensão entre global e local no mundo contemporâneo, com o reforço das identidades nacionais e outras identidades locais (HALL, 2006, 1992, p. 69). Para pensar o mundo contemporâneo, e a mobilidade (AUGÉ, 2009) que lhe está associada, implica percorrer diversas escalas, lugares e tempos configurados por estas duas forças que actuam em estreita relação.

De fato, o mundo da arte tornou-se mais policêntrico (THORNTON, 2010, 2008) ao constituir uma rede dispersa de culturas sobrepostas. Neste sentido, a mobilização vernacular (SMITH, 2011) revela um posicionamento relacional dos artistas no quadro dos fluxos transnacionais e das negociações inter-culturais. Nas palavras de Joana Vasconcelos:

Eu vivo o particular com grande intensidade porque gosto muito de Portugal e gosto muito das coisas que vou encontrando. Por outro lado, Portugal não chega porque é preciso comunicar e a certa altura tens que ir comunicar com os outros, portanto tens que ser global. No fundo a globalização é um caminho é um percurso. Eu sou particular e global. ${ }^{22}$

A globalização tem, tal como apontou Stuart Hall (2006, 1992), um efeito pluralizante, tornando as "identidades mais posicionais" (HALL, 2006, 1992, p. 87).. Ao convocar a cultura e a história de uma nação, os artistas constroem espaços dialógicos desenvolvendo movimentos críticos e reflexivos em torno do seu posicionamento identitário.

Mas nas artes visuais vão habitar outros discursos e práticas que evocam a relação de Portugal com espaços e as histórias das ex-colónias, com particular ênfase com os territórios africanos.

\section{A discussão da nação na arte contemporânea portuguesa II: a interpelação do império}

No início do mês Julho de 2011, Manuel Botelho ${ }^{23}$ (Lisboa, 1950) inaugurou em Cascais, vila próxima da cidade de Lisboa, a exposição Cartas de Amor e Saudade. A exposição encontrava-se organizada em duas salas. Nas paredes do primeiro espaço surpreendia-nos um conjunto de panos de tendas de campanha. Em frente, encontravam-se três fotografias, em grande formato, que invocavam o tempo da Guerra Colonial e 
o movimento de palavras, sentimentos, perdas, entre o "cá" e o que já foi "lá". A segunda sala recriava um ambiente doméstico onde podíamos ouvir algumas palavras trocadas entre territórios e geografias diferenciadas, através de uma instalação sonora que convocava registos epistolares. O texto situava-nos na Guiné na década de 6o. Podíamos escutar:

[...] os homens da minha companhia voltaram a ter contacto com o inimigo. Quando os vi regressar nos Unimog até me assustei, vinham sujos de lama e sangue, as cores das fardas já não se conheciam, as caras eram autênticas máscaras de lama! E vê lá tu, querida, um dos nossos alferes pisou uma mina que lhe arrancou a perna e o pé e teve de ser evacuado de helicóptero para Bissau. [...] Quando se soube a notícia sentiu-se um silêncio profundo e tudo ficou triste, alguns nem puderam suster as lágrimas. (BOTELHO, 2011, p. 31)

Esta exposição serve de mote para introduzir o debate em torno do "Império" na visualidade em Portugal na pós-colonialidade. A experiência histórica do colonialismo marca as práticas artísticas ${ }^{24}$, objectificando-se em estéticas específicas. Estas aludem a uma relação estreita entre nação e império através de uma leitura crítica e reflexiva da memória imperial e dos silêncios sobre a Guerra Colonial em África.

Neste contexto, a nação é discutida nas artes visuais integrando referências ao passado colonial e num continuum colonialismo-pós-colonialismo (VALE DE ALMEIDA, 2002, p. 27), remetendo para a seguinte ideia de $H$. Bhabha: "The Western metropole must confront its post-colonial history, told by its influxo postwar migrants and refugees, as an indigenous or native narrative internal to its national identity" (1994, p. 9). Na mesma linha Manuela Ribeiro Sanches reitera que "a identidade nacional não pode ser dissociada de um passado colonial, bem como o 'lá fora' não deixa de fazer, agora de modo diferente, parte do 'cá dentro"' (SANCHES, 2006, p. 8).

Segundo Margarida Calafate Ribeiro (2004), a construção de uma imagem de Portugal como centro realizou-se através do império, isto é, de Portugal como nação imperial que tal como hoje ocultava uma segunda imagem ligada à experiência de periferia que "imagina o centro", participando dele simbolicamente. Importa sublinhar a especificidade da experiência colonial portuguesa e o facto de Portugal ser um país semi-periférico que se caracterizou por um colonialismo subalterno, cujo império terminou em 1974, com a revolução do 
25 de Abril. Foi a via do império que configurou fortemente as expressões da identidade nacional e, mais tarde, foi pela via da integração na União Europeia que Portugal se imaginou como centro, parafraseando Boaventura Sousa Santos (2002).

Neste quadro, importa questionar como esta dimensão é debatida pelos artistas portugueses e do modo como dão conta do movimento do "centro [que] se desloca para a periferia" (RIBEIRO, 2004, p. 230). Referindo-se a uma exposição anterior ${ }^{25}$, patente no Centro de Arte Moderna da Fundação Calouste Gulbenkian, Manuel Botelho assinala justamente este aspecto:

A reflexão sobre as questões de identidade é uma espécie de infra-estrutura do meu trabalho, desde sempre. Recentemente eu expus na Gulbenkian um trabalho baseado nas mensagens de Natal [dos soldados portugueses durante a guerra colonial]. Eu utilizei as mensagens de Natal por uma razão muito clara: na exposição da Gulbenkian tinha dois grupos de trabalhos: tinha um que tinha os militares a falar e tinha outro onde ninguém falava. Tinha de facto os soldados a falar sem dizer nada, que para mim é a imagem bem acabada desse obscurantismo e dessa incomunicação, do atabafamento desse assunto durante anos. Portugal esteve envolvido numa guerra e nós nunca soubemos nada dessa guerra. As únicas imagens as quais tínhamos acesso eram imagens estereotipadas deles a dizerem uma frase que era invariavelmente a mesma: mandarem as boas festas às famílias e às namoradas. E eles falavam, mas não diziam nada. A gente a única coisa que sabia é que naquele dia, aquela hora aquela pessoa estava viva. Através de uma coisa onde aparentemente se fala, é do silenciamento que eu estou a falar. E tudo isto se liga com o quadro ideológico do fascismo.

Eu tenho estado preocupado com as cicatrizes. E as cicatrizes é aquilo que a gente tem na pele. Interessa-me o soldado que teve caladinho e aguentou. Que veio de lá sem uma perna com os neurónios todos escangalhados. ${ }^{26}$

Assim, a nação é desafiada, reinterpretada, incorporando outras geografias e disseminando sentidos alternativos. Os artistas posicionam-se criticamente perante as lógicas hegemónicas do Estado, afastando-se do tom, por vezes celebratório, da cultura nacional. O debate da identidade nacional através do império traz à colação a subalternidade "doméstica", as "cicatrizes", o povo "subexposto", dando voz voz ao "soldado calado" invocado por Manuel Botelho. Tal como nos livros de 
António Lobo Antunes, o artista denuncia a história dos que ficaram arredados do discurso hegemónico, dominante, interpelando as ruinas do império (RIBEIRO, 2004, p. 62).

Com caracteristicas congéneres o trabalho de Pedro Barateiro (ALMADA, 1979), alude ao universo do conflito colonial. Num projecto que ocupou as ruas de Lisboa, colou em diversos locais da cidade cartazes com a frase "Agradecemos aos nossos clientes que não discutam política em voz alta" (NICOLAU, 2009) ao lado de uma fotografia do pai segurando um bezerro, imagem captada durante a guerra na Guiné. Nas palavras do artista:

Em 2005 e 2006 fiz um projecto em que colei um série de posters na rua onde eu usei uma imagem do meu pai, aquelas tipicas imagens que os soldados traziam da guerra. E eu achava aquilo estranho porque as imagens eram todas muito alegres, em situações muito simpáticas. E aquilo que eu achava que era a vida lá, não era nada daquilo. As imagens que eles mandavam eram imagens para a família. Era uma filtragem. Não havia imagens de edíficios. Pareciam que estavam fechados numa espécie de comunidade. Na verdade interessou-me bastante pensar o que tinha acontecido naquela altura, naquele tempo porque o meu pai falava pouco sobre isso. $\mathrm{Na}$ altura utilizei aquela imagem porque achava que todas as pessoas deviam conhecer. ${ }^{27}$

A relação entre as ex-colónias e o antigo centro imperial é também trabalhada por Pedro Barateiro a partir da desmontagem do quadro ideológico e dos mecanismos de propaganda do fascismo português. $\mathrm{O}$ artista afirma que a história nacional assume centralidade no seu trabalho. Tomando como ponto de partida a instalação video intitulada Composição (2007) afirma:

Interessa-me contextualizar as coisas e como o meu trabalho se insere no contexto actual e universal. [...] Em 2005 e 2006 acabei por me interessar por um conjunto de filmes de propaganda feitos em Angola e Moçambique que se chamavam "Actualidades". Parto do acervo do ANIME [Arquivo Nacional de Imagens em Movimento]. E aqueles filmes, muito curtos, 6 a 9 minutos no máximo, eram obviamente encomendas do Estado português, para propaganda. Pediam a alguns realizadores, uma pequena equipa, para irem filmando. Uma coisa que vai desde os anos 30 aos anos 6o. O que me interessou não foi o som. A determinada altura desliguei, era muito potente, muito 
paternalista, muito desconfortável o discurso de propaganda: Agora a visita do senhor comandante! O que me interessou foram as imagens das vistas áreas, que existiam no meio de todo daquele aparato que acontecia realmente lá. Sem percebermos aqui em território português, haviam imagens que eram cortadas e fugiam completamente a essa vontade que existia do Estado português em mostrar às pessoas cá. ${ }^{28}$

Importa sublinhar que estes artistas debatem o império tendo como ponto de localização e interpelação o Ocidente e a sua história nacional, "no que tudo isto foi para nós"29. Como assinala Manuel Botelho:

Eu, o outro lado, ainda não olhei para ele. Tenho estado a olhar para o nosso umbigo porque eu acho se calhar é essa a minha função. Porque eu penso que no outro lado estão pessoas a pensar no seu próprio umbigo e muito bem. E isto não tem nada a ver com ideologia. A minha ideologia é de esquerda, eu estava nitidamente a favor da libertação dos povos, e sou. A legitimidade dos povos a se auto-determinarem é uma coisa inalianável $[. ..] .^{30}$

Mas a visualidade contemporânea espelha, igualmente, outros posicionamentos próximos de um diálogo com a teoria pós-colonial. Em 2006, o antropólogo José Fernandes Dias afirmava que no domínio da prática artística portuguesa estávamos perante "um silêncio e a invisibilidade sobre o não-ocidental" (2006, p. 330). Contudo, ao autor identificava algumas excepções, nomeadamente Ângela Ferreira e Vasco Araújo ${ }^{31}$ (Lisboa, 1975).

A interlocução com o "popular" de matriz rural presente na prática artística de Ângela Ferreira, exposta acima, pode ser lida igualmente através da perspectiva pós-colonial. E aqui a dimensão biográfica e diaspórica do seu trabalho é particularmente evidente:

"Quando volto para viver cá [Portugal] mais permanentemente, percebo os apectos da cultura popular apropriados pelo Estado Novo ${ }^{32}$. Interessa-me o Estado Novo porque é crucial no colonialismo, porque é a cultura popular que é exportada para África. E eu bebi dessa cultura."33

Na mesma linha, numa carta datada de 15 de Setembro de 2001, endereçada ao Serviço de Belas Artes da Fundação 
Calouste Gulbenkian, afirma: "grande parte da minha obra tem lidado precisamente com as sobreposições de identidade criadas pela História portuguesa." 34

Nos finais da década de 9o, a artista dá início a uma reflexão aprofundada sobre a política cultural em África, a história colonial e os seus ecos contemporâneos. Um discurso pós-colonial torna-se axial no seu trabalho sublinhando a sobreposição e deslocação de territórios de diferença (LAPA \& RENTON, 2003, p. 37) presentes, por exemplo, nas obras Maison Tropical (2007) e Model \#3 for Propaganda Stand, Screen and Loudspeaker Platform Celebrating a Post-Indepen-dence $U_{t o p i a}{ }^{35}$. Esta última escultura integra um projecto dedicado a Moçambique - For Mozambique - na qual a artista mobiliza os tempos subsequentes à Revolução Russa e o período pós-independência de Moçambique, através do filme Makwayela (1977) de Jean Rouch e Jacques d'Arthuis. Segundo Ângela Ferreira, a temática central da sua obra são "as relações culturais, as relações de identidade entre África e a Europa" ${ }^{36}$.

Um posicionamento congénere é possível identificar na prática artística de Vasco Araújo. Na instalação-vídeo Jardim (2004), a câmara palmilha a vegetação do Jardim Botânico Tropical situado em Belém (Lisboa). As personagens são estátuas, figuras de negros, realizadas nos anos 40 por altura da Exposição do Mundo Português, que funcionavam como figuras de convite localizadas à entrada dos pavilhões das colónias. A partir de fragmentos de diálogos extraídos da Ilíada e da Odisseia de Homero lidos por portugueses, nascidos em Portugal de pais africanos (DIAS, 2006), Vasco Araújo alude ao passado colonial e às reconfigurações identitárias no quadro do pós-colonialismo.

Já na série escultórica Debret (2009) são convocadas outras geografias e tempos. Constituída por 15 esculturas, Debret é o resultado de uma interpretação da relação social entre brancos e negros, portugueses e africanos, senhores e escravos no Brasil do século XIX (ARAÚJO, 2010). Nesta série, o artista convida, ainda, as palavras de Padre António Vieira num diálogo com a condição pós-colonial enunciando as várias vozes em presença. Vasco Araújo olha para as obras de Debret atento à forma "como interagiam em sociedade e na intimidade, os senhores e os escravos no Brasil do século XIX", interrogando o teatro de relações, as relações de poder e obediência. Revisita o passado colonial, esteticizando o sofrimento do outro (Pires do Vale, 2010). 


\section{Notas finais}

Ao longo deste artigo foram identificados e analisados processos de interlocução com a nação nas práticas artísticas contemporêneas em Portugal. Este diálogo, nas dimensões aqui identificadas, permite aceder às dinâmicas e práticas identitárias que sinalizam o posicionamento dos artistas no mundo contemporâneo. Tal como referiu Meskimmon (2011), ao analisar o "domestic turn" da arte contemporânea: "they participate in a critical dialogue between ethical responsability, locational identity and what I should call 'cosmopolitan imagination' (2011, p. 5).

Neste sentido, e retomando o argumento de Benedict Anderson (1991), os artistas imagimam a nação de forma selectiva, activam um conceito de nação diferenciado, permitindo perceber o mundo contemporâneo como um solo de ambivalências. Tal como afirmou Robbins aludindo às dinâmicas da globalização:

Globalization is profoundly transforming our apprehension of the world: it is provoking a new experience of orientation and disorientation, new senses of placed and placeless identity. The global-local nexus is associated with new relations between space and place, fixity and mobility, centre and periphery, 'real' and 'virtual' space, 'inside' ans 'outside', frontier an territory. This, inevitability, has implications for both and individual collective identities and for the meaning of coherence of community. (ROBINS, 1999, p. 27)

A nação surge, não como uma entidade fixa ou insular, mas como uma plataforma que permite expressar interpelações e desconfortos vários com a globalização, com o colonialismo e Guerra Colonial, com as assimetrias de poder, com as lógicas de poder do Estado, com fascismo português, reforçando a ideia de que as práticas artísticas são formas privilegiadas de classificar e interpretar o mundo.

\section{Referências}

ANDERSON, B., Imagined Communities. Reflections on the Origin and Spread of Nationalism, Nova Iorque, Verso, 1991 [1983]. APPADURAI, A., Modernity at Large, Cultural Dimensions 
of Globalization, Minneapolis, London, University of Minesota Press, 1996.

ARAÚJO, V., Debret, Lisboa, Assírio e Alvim - Galeria Filomena Soares, 2010.

AUGÉ, Marc, Pour une anthropologie de la moblité, Paris, Éditions Payot, 2009.

BECKER, H., Art Worlds, Berkeley, Los Angels, California, University of California Press, 1982.

BHABHA, H., The Location Of Culture. Londres, Nova Iorque, Routledge, 1994.

BOTELHO, M., Cartas de Amor e Saudade [catálogo de exposição], Centro Cultural de Cascais, Fundação D. Luís, 2011. BUSCATTO, M., "L'art et la manière : ethnographies du travail artistique" in Ethnologie Française, L'art au Travail, I, 2008, p. 5-13.

DIAS, J.A.F., “ Pós-colonialismo nas artes ou talvez não”. In: Sanches, M.R. (eds), Portugal não é um País Pequeno. Contar o Império na pos-colononialidade, Lisboa, Cotovia, 2006, p. 317:337.

DIDI-HUMERMAN, G., "Coisa pública, Coisa dos povos, Coisa plural”. In: A República Porvir. Arte, Política e Pensamento para o Século XXI, Lisboa, Fundação Calouste Gulbenkian, 2011, p. 41-70.

FEIO, C. N., A A and away [catálogo de exposição], Londres, Transition Editions.

GARCIA CANCLINI, N., La sociedad sin relato. Antropologia y estética de la inminencia, Madrid, Katz Editores, 2010.

GARCIA CANCLINI, N. "Remaking Passports. Visual Thought in the debate of multiculturalism". In: Mirzoeff, Nicholas (eds), The Visual Culture reader, London, Routledge, 2005 [1998], p. 180-189.

GELL, A., Art and Agency, an Anthropological Theory, Oxford, Clarendon Press, 1998.

HALL, S., A Identidade Cultural na Pós-Modernidade, Rio de Janeiro DP\&A Editores, 2006 [1992].

HALL, S., "When was the "Post-Colonial"? Thinking at the Limit”. In: CHAMBERS, L., CURTI, L. (eds.), The Post-colonial question, London, New York, Routledge, 2006 [1996], p. 242-26o.

HALL, S.; Evans, J. (eds.), Visual Culture. The reader, London, Sage Publications, 2004 [1999].

Joana Vasconcelos, Sem rede [catálogo de exposição], Museu Colecção Berardo, 2010. 
LAPA, P.; RENTON. A., Ângela Ferreira. Em sítio Algum/ No Place at all [catálogo de exposição], Lisboa, Museu do Chiado - Museu Nacional de Arte Contemporânea, 2003.

LEOUSSI, A. S.,"The ethno-cultural roots of national art”, Nations and Nationalism, 10 (1/2), 2004, p. 143-159.

LÖFGREN, O., "The Nationalization of Culture", Ethnologia Europaea, XIX, 1989, p. 5-24.

MACCLANCY, J. (eds.), Contesting Art. Art, Politics and Identity in the Modern World, Oxford, New York, Berg, 1997.

MARCUS, G. E.; MYERS, F. R., (eds.), The Traffic in Culture. Refiguring Art and Anthropology, Berkeley, Los Angels, London, University of California Press, 1995.

MESKIMMON, M., Contemporary Art and Cosmopolitan Imagination, Londres, Nova Iorque, Routledge, 2011.

MITCHELL, W.J.T., "The Pictorial Turn" in Picture Theory, Chicago, University of Chicago Press, 1994.

MITCHELL, W.J.T., "Showing Seeing: a critique of visual culture". Journal of Visual Culture, London, Thousand Oaks, CA, New Delhi, Sage Publications, 2002, p.165-181.

MORPHY, Howard; PERKINS, Morgan (eds.), The Anthropology of Art A Reader, Blackwell Publishing, 2006.

NICOLAU, Ricardo, "O Leão Partido - Porque deixaram Ornamento e Design de ser Crime”. In Teoria da Fala. Pedro Barateiro, Porto, Fundação Serralves, 2009, p. 75-99.

PINHARANDA, J., "O declínio das vanguardas: dos anos 50 ao fim do milénio", PEREIRA, P. (dir.), História da Arte Portuguesa, Volume III, Circulo de Leitores, 1997, p. 593-649.

PINHARANDA, J., "Vamos ver o povo...”. In: NEVES, José (coord.), Como se faz um povo, Lisboa, Edições Tinta -da China, 2010, p. 385:399.

RIBEIRO, M. C, Uma História de Regressos. Império, Guerra Colonial e Pós-colonialismo, Porto, Afrontamento, 2004.

SANCHES, M. R. (orgs.), Portugal não é um País Pequeno. Contar o Império na pos-colononialidade, Lisboa, Cotovia, 2006.

SANTOS, B.,"Entre Prospero e Caliban: Colonialismo, pós-colonialismo e inter-identidade". In RAMALHO, M. I. e RIBEIRO, A. S. (orgs.), Entre ser e estar: raízes, percursos e discursos da identidade. Porto: Afrontamento, 2002, pp. 23-85.

SCHNEIDER, A., Appropriation as Practice: Art and Identity in Argentina, Palgrave Macmillan, 2006.

SCHNEIDER, A., "On 'appropriation'. A critical reappraisal of the concept and its application in global art practices", Social Anthropology (2003), 11, 2, 2003, pp. 215:229.

SCHNEIDER, A.; WRIGHT, C. (eds.), Contemporary Art and 
Anthropology, Oxford, New York, Berg, 2006.

SILVA, R. H., 1997, "Romantismo e pré-naturalismo”. In: PEREIRA, P. (dir.), História da Arte Portuguesa, Volume III, Circulo de Leitores, 1997, p. 329:367.

SMITH, A. D., A Identidade Nacional, Lisboa, Gradiva, 1997 [1991]. SMITH, A. D., "When is a nation". In Geopolitics, 7 (2), 2002, p. 5-32.

SMITH, A. D., 2011, "National Identity and Vernacular mobilisation in Europe", Nation and Nationanalism, 17 (2), p.223-256.

STOCKING, G., "Afterword: A view from the Center", Ethnos, 47, 1982, p. 7-86.

THIESSE, A.-M., A Criação das Identidades Nacionais, Lisboa, Temas e Debates, 2000.

THORNTON, S., Siete días en el mundo del arte, Espanha, Edhasa, 2010 [2008].

RANCIÈRE, J., O Espectador Emancipado, Lisboa, Orfeu Negro, 2010.

ROBINS, K., "Tradition and Cultural Translation. National Culture in its Global Context”. In: BOSWELL, D.; EVANS, J., Representing the Nation: a Reader. Histories, heritage and Museums, London, New York, Routledge, 1999, p. 15-32.

RUBIO, A. P., "Do Micro ao Macro e Vice-Versa. Uma conversa entre Agustin Pérez Rubio e Joana Vasconcelos”. In Joana Vasconcelos, Lisboa, ADIAC Portugal, 2007, pp.38-61.

VALE DE ALMEIDA, M., "O Atlântico Pardo. Antropologia, pós-colonialismo e o caso "lusófono" in BASTOS, Cristiana; FELDMAN-BIANCO, Bela (coord.), Trânsitos coloniais: diálogos críticos luso-brasileiros, Lisboa, Imprensa de Ciências Sociais, 2002, p. 23-37.

\section{Fontes arquivísticas}

Fundação Calouste Gulbenkian - Serviço de Belas Artes

Processos: ․o 4894; N. 7168, N. 10736.

\section{Entrevistas}

Barateiro, Pedro, 2010

Botelho, Manuel, 2011

Feio, Carlos Noronha, 2010

Ferreira, Ângela, 2008

Vale, João Pedro, 2010

Vasconcelos, Joana, 2009 
1. O presente artigo insere-se na minha investigação de pós-doutoramento em antropologia intitulada: "Diálogos com a nacão nas práticas e discursos da arte contemporânea portuguesa" (Ref.SFRH/BPD/37456/2007) financiado por Fundos Nacionais através da FCT - Fundação para a Ciência e a Tecnologia.

2. A Guerra Colonial foi travada, desde 1961, em territórios africanos, prolongando-se até 1974, ano do terminus da ditadura. Existiam frentes de batalha na Guiné-Bissau, Angola e Moçambique. Além destes países, também Cabo Verde, São Tomé e Príncipe, Timor-Leste e Macau faziam parte do império colonial português.

3. Por economia de texto não é possível, no quadro deste artigo, uma apresentação biográfica pormenorizada dos artistas analisados pelo que ao lọngo do texto são fornecidos alguns elementos biográficos e referenciađas, sempre que existam, as páginas web dos artistas.

4. Em termos metodológicos, optou-se por uma estratégia múltipla, entrevista em profundidade junto de artistas plásticos, a observação presencial de acontecimentos relacionados com as práticas artísticas. Procedeu-se, ainda, ao recenseamento e à pesquisa de diferentes fontes documentais.

\section{Ver www.joanavasconcelos.com}

6. Ver Joana Vasconcelos, Sem rede [catálogo de exposição], Museu Colecção Berardo, 2010.

7. http://www.facebook.com/\#!/pages/Joana-Vasconcelos/3004998 43890 ?ref=ts. Consultado a 19 de Abril de 2010 e 2 de Agosto de 2010.

8. No início do século XX, os debates em torno da ideia de Portugal continuavam acesos e eram também representados pelos artistas plásticos que tinham dado corpo a movimentos estéticos iniciados no século anterior, como o naturalismo - que continuaria a granjear visibilidade ao longo da primeira metade do século XX (Silva, 1997:352) - no qual a cultura popular de matriz rural adquiria centralidade.

Paradoxalmente, nas vésperas da Primeira Guerra Mundial, o modernismo, que surge como movimento de ruptura com o naturalismo, viria apropriar-se dos temas e objectos populares inaugurando, pela via da sedução formal, uma relação distinta com a cultura popular portuguesa, análoga à que as vanguardas internacionais tinham estabelecido com a designada "arte africana".

De facto, numa continuidade com o século XIX, assiste-se a uma apropriação do popular de matriz rural, num movimento de representação da autenticidade da nação. Esta tendência para representar o "autêntico" encontrará o seuu expoente máximo no Estado Novo, com a sua política folclorista centrada nos conceitos de nação e de tradição que o modernismo, dominado agora pelo regime, viria a cristalizar plástica e ideologicamente na Exposição do Mundo Português.

Contrariando esta tendência, o movimento neo-realista surge na década de 40 como reflexo das propostas do "realismo socialista", sugerindo uma contra-imagem de Portugal reveladora de um país coarctado, pelo que a representação dos aspetos da cultura popular apropriados pelos diferentes artistas irá aproximar-se do documentalismo (Pinharanda, 1997:598). Mas nos longos anos de vigência do regime ditatorial, a par das afinidades entre arte e poder, eclodiram e coexistiram outros movimentos, marcados pelos debates entre figurativos e abstractos, entre neo-realistas e surrealistas nos quais a percepção da cultura popular não se fez, por vezes, de forma tão imediata devido ao próprio carácter dos posicionamentos estéticos. 
A autonomização da iniciativa artística em relação à ideologia do Estado Novo, que irá caracterizar o período do pós-guerra, criará condições para uma diversidade de escolhas temáticas e formais que se vão exprimir no campo artístico português, sobretudo a partir dos anos 6o, no qual a relação cultura popular - artes plásticas se encontra mais disseminada, mas não menos relevante (cf. Pinharanda, 2010) até à actualidade.

9. Entrevista J.V., 2009.

10. Entrevista J.V., 2009.

11. Ver www.carlosnoronhafeio.co.uk

12. Entrevista C.N.F., 2010.

13. Entrevista C.N.F., 2010.

14. Ver também reflexão de Marcus e Myers (1995).

15. Ver www.joaopedrovale.com

16. Entrevista J.P.V., 2010.

17. De origem portuguesa fez a sua formação superior na África do Sul (Capetown), vivendo em Lisboa.

18. A exposição recebeu o título A Propósito de..., tendo se realizado no Centro de Arte Moderna José Azeredo Perdigão em Lisboa no ano de 1990.

19. Entrevista A.F., 2008.

20. Relatório intitulado Fase Final - projecto baseado nos painéis "Emigração", de Almada Negreiros situados na Gare Marítima Rocha de Conde de Óbidos, que inclui também a produção da exposição "Portugal dos Pequenitos", 1996, Arquivo SBA, Proc. N. 7168.

21. Anexo I ao Boletim de Inscrição para Bolsa de Estudo de Especialização, 1989, Serviço de Belas Artes, Arquivo SBA, Proc. N. 4894.

22. Entrevista J.V., 2009.

23. Ver www.manuelbotelho.com

24. Para uma discussão em torno do pós-colonialismo nas artes visuais em Portugal ver Fernandes Dias (2006).

25. Exposição intitulada Professores. Centro de Arte Moderna Fundação Calouste Gulbenkian (14.OUT.2010-02.JAN.2011)

26. Entrevista M. B., 2011.

27. Entrevista P. B., 2010.

28. Entrevista P. B., 2010.

29. Entrevista M. B., 2011.

30. Entrevista M. B., 2011.

31. Ver www.vascoaraujo.org

32. "Estado Novo" é a designação que nomeia o regime político autoritário que se estabeleceu em Portugal no período entre 1933 
a 1974. Foi pela revoluçã̃o do 25 de Abril, também conhecida como "Revolução dos Cravos".

33. Entrevista A.F., 2008

34. Serviço de Belas Artes, Arquivo SBA, Proc. N. 10736.

35. Maison Tropicale foi a sua proposta para representar oficialmente Portugal na 52nd International Art Exhibition de Veneza (2007). For Mozambique model\# 3 foi a obra apresentada à Bienal de Artes de São Paulo.

36. Entrevista A.F., 2008.

Recebido em: 02/03/12

Aceito em: 20/03/12 
SÓNIA VESPEIRA DE ALMEIDA

sonia.almeida@fcsh.unl.pt

Investigadora do CRIA (Centro em Rede de Investigação em

Antropologia) e Professora Auxiliar Convidada no Departamento

de Antropologia da Faculdade de Ciências Sociais e Humanas -

Universidade Nova de Lisboa. 